\title{
Influence of Plantain Pseudostem Fibres and Lime on the Properties of Cement Mortar
}

\author{
Humphrey Danso (iD \\ Department of Construction \& Wood Technology, University of Education Winneba, P.O. Box 1277, Kumasi, Ghana \\ Correspondence should be addressed to Humphrey Danso; dansohumphrey@yahoo.co.uk
}

Received 27 May 2020; Accepted 28 August 2020; Published 9 September 2020

Academic Editor: Nadezda Stevulova

Copyright (c) 2020 Humphrey Danso. This is an open access article distributed under the Creative Commons Attribution License, which permits unrestricted use, distribution, and reproduction in any medium, provided the original work is properly cited.

\begin{abstract}
This study investigated the properties of cement mortar with lime reinforced with plantain pseudostem fibres. Experimental specimens with $0,0.25,0.5,0.75$, and $1 \%$ fibre contents by weight of sand and $10 \%$ lime content by weight of cement were prepared and tested on 7, 14, 21, and 28 days of curing for density, tensile strength, compressive strength, SEM, and EDS. The $0.25 \%$ plantain pseudostem fibre reinforced mortar achieved 23.4\% compressive strength improvement over unreinforced mortar specimens. There was between 6.89 and $13.80 \%$ increase in tensile strength of the plantain pseudostem fibre reinforced mortar over the unreinforced mortar specimens. A positive linear correlation was found between the compressive strength and tensile strength of cement mortar reinforced with plantain pseudostem fibres and lime with coefficient of determinant $\left(R^{2}\right)$ values between 0.909 and 0.869 . It was also observed that the plantain pseudostem fibre reinforced mortar specimen had some microcracks and voids from the SEM analysis. Furthermore, EDS analysis showed the presence of calcium silicate hydrate with a $\mathrm{Ca} / \mathrm{Si}$ ratio of between 1.02 and 2.49, and $\mathrm{Al} / \mathrm{Si}$ ratio of between 0.76 and 0.81 as the main oxide. It therefore concluded that the incorporation of plantain pseudostem fibre and lime positively influenced the properties of the cement mortar with the $0.25 \%$ fibre content being recommended for construction application.
\end{abstract}

\section{Introduction}

The demand for alternative building materials that are affordable, environmentally friendly, and abundantly available is on the rise. Studies have responded to this demand with research studies being carried out to investigate the suitability of some plant residue for use in concrete and mortar [1]. More attention should be paid to the application of natural fibres as building materials for the purpose of conserving energy [2]. The application of natural fibre in mortar and concrete as admixture can contribute to the reduction of environmental challenges caused by waste disposal [3]. Today, the advancement of cement-based composites has seen innovations and techniques in designs that are economically and environmentally responsive and seek to utilize raw materials that are abundantly available. The use of plant residue by construction industry helps in achieving sustainable intake of building materials [4]. The utilization of local building materials is one of the potential ways of supporting sustainable development in emerging economies $[5,6]$.

An important plant residue for utilization in construction materials is pseudostem which is usually obtained from banana and plantain plants. Pseudostem is the trunk of banana or plantain plant which forms tightly wrapped overlapping sheaths. The trunk (pseudostem) contains hard fibrous overlapping layers which are spirally arranged to fold around the centre pith [1]. The pseudostem is made up of bonded filaments with cellulosic forms, hemicelluloses, and lignin [7]. The pseudostem contains woody fibre-based lignocellulose material that possesses good properties for construction application.

Studies have shown that banana pseudostem fibres can be used to reinforce the properties of cement composites. Malarvizhi et al. [8] investigated the properties of concrete slabs reinforced with banana fibres, which yielded a positive effect with significant improvement in the compressive and tensile strengths. Kumaat et al. [3] studied the characteristics 
of concrete reinforced with banana stem fibre, which obtained improvement in flexural and tensile strengths of concrete. Zhu et al. [2] studied the properties of reinforced cement composites with banana fibres and found improvement in flexural and fracture toughness which are adequate for use as building material. Mostafa and Uddin [5] investigated the properties of reinforced compressed earth blocks with banana fibres and recorded improvement in the flexural and compressive strengths of the blocks. Tirkey and Ramesh [9] used banana fibres to reinforced concrete and obtained increased compressive strength. Mukhopadhyay and Bhattacharjee [10] investigated the influence of concrete reinforced with banana fibres and achieved an improved compressive strength and a low volume fraction of the concrete.

From the aforementioned, it can be seen that within the pseudostem plants, extensive research has been carried out with the use of banana fibres. There has not been enough research in the application of plantain pseudostem fibres which have similar properties to the banana pseudostem fibres in concrete and mortar. It is therefore important to advance the discourse of pseudostem fibre application in concrete and mortar by the introduction of plantain pseudostem fibres in cement-base matrix. This study, therefore, investigates the properties of cement mortar reinforced with plantain pseudostem fibres with addition of lime, to determine the influence the fibres have on the cement mortar. The study contributes to knowledge in the application of pseudostem plant fibres in sustainable construction materials. Plantain (Musa paradisiaca) is a common plant that grows well in sub-Sahara African, Asia, and other parts of the world. The plantain pseudostem residue is abundantly available, affordable, and possesses mechanical properties which can contribute to sustainable construction materials applicable in building construction.

\section{Experimental Materials and Procedure}

2.1. Experimental Materials. Sand, plantain pseudostem fibres, cement, lime, jute sack, and water are the main materials used for preparing the mortar for making specimens for the study. Pit sand that conforms to BS EN 12620 [11] requirements was used for preparing the mortar. Plantain pseudostem fibres were prepared from plantain pseudostem residue at a farm in Kumasi, Ghana. The residue was soaked in water for 24 hours, and the fibres were mechanically extracted, washed, and dried in the sun. Photographs of the sample plantain pseudostem fibres and the scanning electron microscope (SEM) image of a single fibre are shown in Figure 1. A critical observation of the SEM image of the single fibre shows continuous microstrip patterns with slight indents on the surface of the fibre. This feature of the fibre is good to ensure a good bond between the fibre and the matrix. The average diameter of the fibres measured is $0.65 \pm 0.26 \mathrm{~mm}$, specific weight is $0.35 \mathrm{~g} / \mathrm{cm}^{3}$, and water absorption of about $245 \%$. The fibres were cut to length of aspect ratio of $100(65 \mathrm{~mm})$. Type I Portland cement of grade 32.5R produced by Ghana Cement (GHACEM) in accordance with BS-12 [12] was purchased in the market for preparing the mortar. Locally available lime, calcium hydroxide $\left(\mathrm{Ca}(\mathrm{OH})_{2}\right)$ with $95 \% \mathrm{CaO}$, was also purchased in the market for preparing the mortar. Tap water was used for preparing the mortar and curing of the specimens together with jute sack.

\subsection{Experimental Procedure}

2.2.1. Preparation of Mortar and Specimens. Weight batching was used for measuring the materials for preparing the mortar. A mix ratio of $1: 3$ (cement: sand) was used. The quantity of lime used was $10 \%$ by weight of cement, as a replacement of cement. Plantain pseudostem fibre quantities used as reinforcement in the mortar are $0.25,0.5,0.75$, and $1 \%$ weight of sand, as replacement of sand with $0 \%$ fibres as control. Water-cement ratios of 0.6 and 0.7 were used for the control and treatments, respectively. The control mix used less water-cement ratio (0.6) because it did not contain lime and fibre. The various mix designs and their corresponding quantities of materials used for preparing the mortars are shown in Table 1. Mechanical mixing was adopted for preparing the mortar to ensure homogenous mix. For each mix design, the materials were weighed and the plantain pseudostem fibres were immersed in water overnight. The immersion of the fibres in water was to prevent the fibres from quick absorption of water in the fresh mortar as it has very high water absorption rate. One-third quantity of water was first poured in the mixing drum and the quantity of cement was added while the drum was rotating slowly. The quantity of lime was added, followed by the fibres and then the quantity of sand added. The remaining two-third of water was added and the speed of the rotating drum increased till a uniform mixture was obtained. The mortars were used to prepare specimens (cubes and cylinders), as shown in Figure 2 (a). $100 \times 100 \times 100 \mathrm{~mm}$ cube specimens and cylinder specimens of length $200 \mathrm{~mm}$ and diameter $100 \mathrm{~mm}$ were moulded in accordance with BS EN 12390-2 [13]. The quantity specimens prepared was 190 (120 cubes and 70 cylinders), as shown in Table 2. After the specimens were set, they were demoulded and covered with wet jute sacks for curing (Figure 2(b)). The jute sack was kept damp throughout the curing period.

2.2.2. Testing of Specimens. The specimens were tested for density, compressive strength, and tensile strength after curing for 7, 14, 21, and 28 days. BS EN 12390-7 [14] procedure was followed to determine the dry density of the cube specimens after drying to obtain a uniform mass. Three replicates were selected, weighed, and the densities calculated for each variable and their averages used for plotting a graph, and the densities lower and upper ranges were used as the error bars on the graph. The study used BS EN 12390-3 [15] as a guide in determining the compressive strength of the cube specimens. The specimens were centrally placed in the Servo Hydraulic Universal Testing Machine and $0.05 \mathrm{kN} /$ $\mathrm{mm}^{2}$ load speed applied till the fracture of the specimens, as shown in Figure 2(c). The average of three replicate test values was recorded and used for plotting a line graph using 


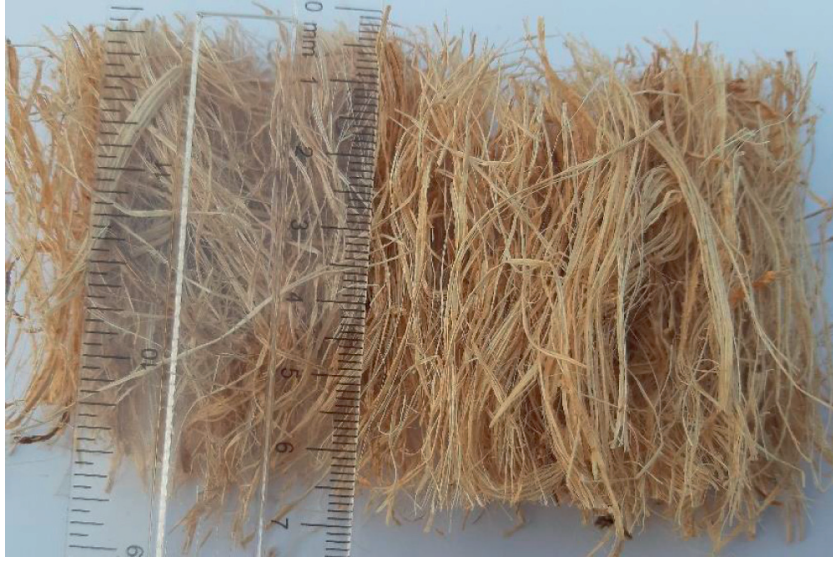

(a)

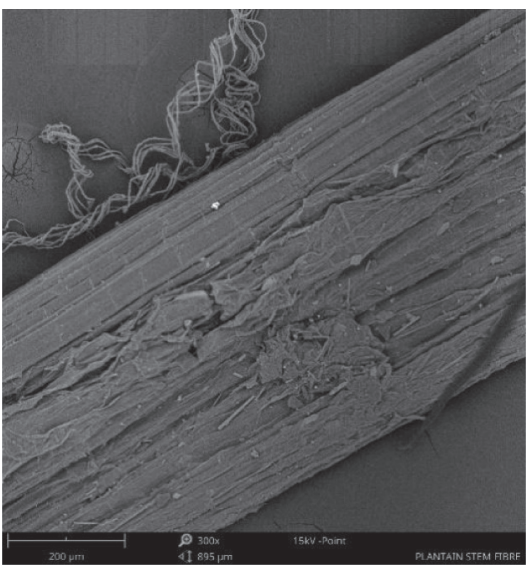

(b)

FIGURE 1: Photograph of plantain pseudostem fibres and SEM image (300x) of a single fibre. (a) Cut fibre photograph. (b) Single fibre SEM image.

TABLE 1: Mix design and quantities of materials.

\begin{tabular}{|c|c|c|c|c|c|c|}
\hline \multirow{2}{*}{ Mix design } & \multirow{2}{*}{$\%$ fibre Content } & \multicolumn{5}{|c|}{ Materials content $(\mathrm{kg})$} \\
\hline & & Sand & Fibre & Cement & Lime & Water \\
\hline M-0 & 0.00 & 48.900 & - & 16.30 & - & 8.15 \\
\hline M-0.25 & 0.25 & 48.737 & 0.163 & 14.67 & 1.63 & 9.78 \\
\hline M-0.5 & 0.50 & 48.574 & 0.326 & 14.67 & 1.63 & 9.78 \\
\hline M-0.75 & 0.75 & 48.411 & 0.489 & 14.67 & 1.63 & 9.78 \\
\hline M-1 & 1.00 & 48.248 & 0.652 & 14.67 & 1.63 & 9.78 \\
\hline
\end{tabular}

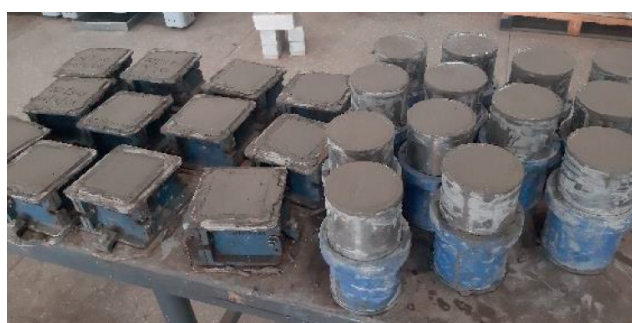

(a)

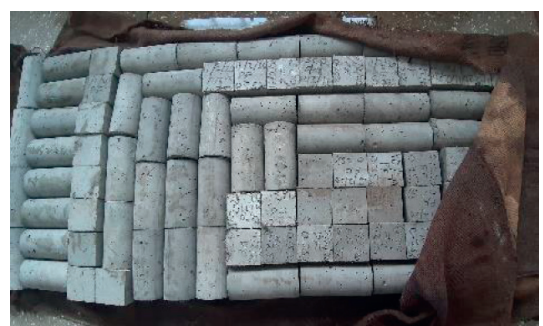

(b)

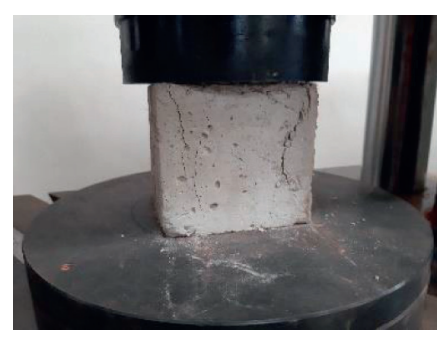

(c)

FIgURE 2: Preparation and testing of specimens. (a) Moulding of specimen. (b) Curing of specimen. (c) Compressive strength test setup.

TABLE 2: Quantity of specimens prepared.

\begin{tabular}{|c|c|c|c|c|c|c|}
\hline \multirow{2}{*}{ Mix design } & \multicolumn{5}{|c|}{ Types of test } & \multirow{2}{*}{ Total } \\
\hline & Dry density & Compressive strength & Tensile strength & SEM & EDS & \\
\hline $\mathrm{M}-0$ & 12 & 12 & 12 & 1 & 1 & 38 \\
\hline M-0.25 & 12 & 12 & 12 & 1 & 1 & 38 \\
\hline M-0.5 & 12 & 12 & 12 & 1 & 1 & 38 \\
\hline M-0.75 & 12 & 12 & 12 & 1 & 1 & 38 \\
\hline M-1 & 12 & 12 & 12 & 1 & 1 & 38 \\
\hline \multirow{2}{*}{ Total } & 60 & 60 & 60 & 5 & 5 & 190 \\
\hline & \multicolumn{2}{|c|}{120 cubes } & \multicolumn{3}{|c|}{70 cylinders } & \\
\hline
\end{tabular}

SEM: scanning electron microscope; EDS: energy dispersive spectrometer. 
Microsoft Office Professional Plus Excel (V 16). Stress-strain graph was also plotted out of the compressive stress and strain values obtained. BS EN 12390-6 [16] procedure was used to guide the tensile strength test conducted with cylinder specimens. The specimens were longitudinally placed in ADR 1500/2000 Testing Machine and $0.05 \mathrm{kN} / \mathrm{mm}^{2}$ load speed applied till the fracture of the specimens. The average of three replicates' test values was recorded and used for plotting a line graph using Microsoft Office Professional Plus Excel. The correlation between the compressive strength and the tensile strength of the specimens was determined using Microsoft Office Professional Plus Excel. One-Way ANOVA tests were conducted to determine the significant differences between the control and the experimental variables using All Pairwise Multiple Comparison procedure. Microscopic and oxides composition tests were also conducted with SEM and energy dispersive spectrometer (EDS) analysis on the specimens.

\section{Results}

3.1. Density. The average dry densities of the $0 \%$ (control) specimens $\left(2167-2190 \mathrm{~kg} / \mathrm{m}^{3}\right)$ were higher than the fibre replacement of sand by $0.25,0.5,0.75$, and $1 \%$, as shown in Figure 3 . The 0.25 and $0.5 \%$ fibre replacement of sand recorded slightly better average densities $\left(2051-2063 \mathrm{~kg} / \mathrm{m}^{3}\right)$ and $\left(2044-2066 \mathrm{~kg} / \mathrm{m}^{3}\right)$, respectively. The trend of the result is consistent with the results found in some studies $[2,17,18]$. Danso et al. [19] ascribe the reduced densities in the fibre reinforced specimens to low specific weight of fibres as compare to the matrix. Therefore, as the fibre content increases, the density of the specimen is likely to reduce. Irrespective of the differences in densities, all the specimens recorded values that were more than $2000 \mathrm{~kg} / \mathrm{m}^{3}$, which are acceptable density values for cement mortar for structural works.

3.2. Compressive Strength. The compressive strength of all the mix designs increased by age from 7 days to 28 days of curing, as shown in Figure 4. This shows a normal strength development of cement and lime due to hydration caused by water mixed with the binders. The fibre replacement of sand by $0.25,0.5$, and $0.75 \%$ obtained better compressive strength of $14.33,13.89$, and $12.85 \mathrm{MPa}$, respectively, over the control specimens of $11.61 \mathrm{MPa}$ on the 28 -day curing, as shown in Table 3. In quantitative terms, this translates into 23.4, 19.7, and $10.7 \%$ improvement, respectively, for $0.25,0.5$, and $0.75 \%$ fibre reinforced cement mortar specimens over unreinforced mortar specimens. The result clearly indicates that the $0.25 \%$ plantain pseudostem fibre-reinforced lime cement mortar obtained an optimum compressive strength. The result is consistent with the study by Ozerkan et al. [20] which obtained similar result for mortar reinforced with palm fibres, and another study [18] which investigated the properties of mortar reinforced with hemp fibres. Çomak et al. [18] attributed the increased compressive strength to the fibres orientation and long length distribution in the cement mortar which provides better performance specimens with less microcracks. Conversely, there was reduction

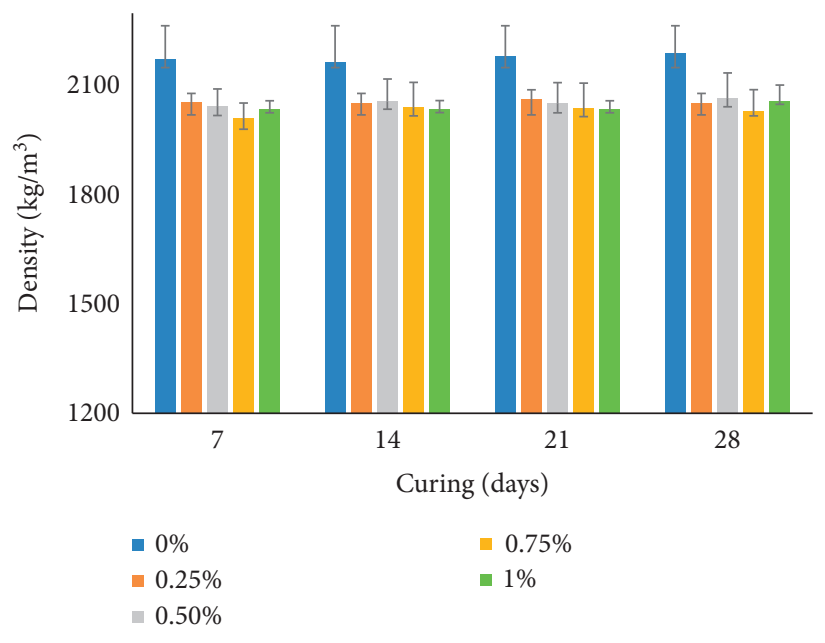

Figure 3: Dry density of the specimens.

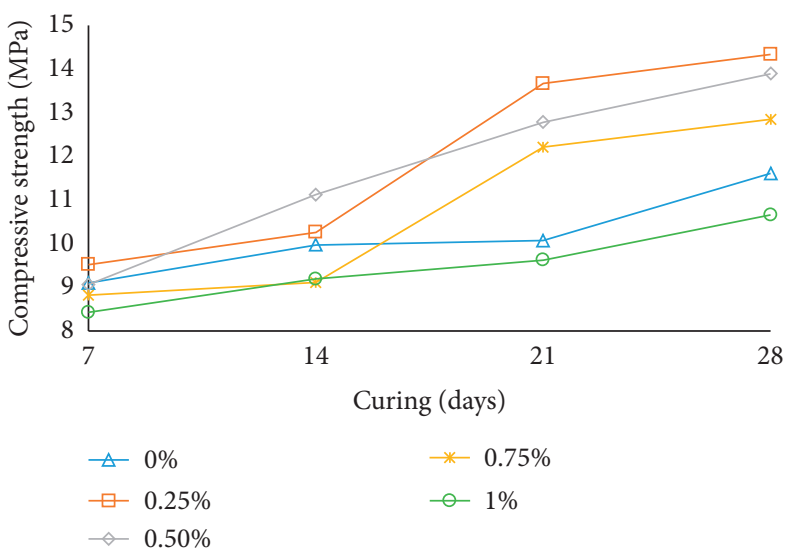

FIGURE 4: Compressive strength of specimens.

TABle 3: Descriptive and One-Way RM ANOVA of compressive strength.

\begin{tabular}{|c|c|c|c|c|}
\hline $\begin{array}{l}\text { Specimen, mixture } \\
(\%)\end{array}$ & $N$ & $\begin{array}{l}\text { Mean } \\
(\mathrm{MPa})\end{array}$ & $\begin{array}{l}\text { Std } \\
\text { Dev }\end{array}$ & SEM \\
\hline 0 & 3 & 11.610 & 0.356 & 0.206 \\
\hline 0.25 & 3 & 14.327 & 0.258 & 0.149 \\
\hline 0.5 & 3 & 13.893 & 0.260 & 0.150 \\
\hline 0.75 & 3 & 12.850 & 0.100 & 0.057 \\
\hline 1 & 3 & 10.660 & 0.200 & 0.115 \\
\hline \multicolumn{5}{|c|}{ Multiple comparisons versus control (Holm-Sidak method) } \\
\hline Comparison & $\begin{array}{l}\text { Diff of } \\
\text { means }\end{array}$ & $T$ & $p$ & $p<0.050$ \\
\hline $0 \%$ vs. $0.25 \%$ & 2.717 & 17.881 & $<0.001$ & Yes \\
\hline $0 \%$ vs. $0.5 \%$ & 2.283 & 15.545 & $<0.001$ & Yes \\
\hline $0 \%$ vs. $0.75 \%$ & 1.240 & 9.327 & $<0.001$ & Yes \\
\hline $0 \%$ vs. $1 \%$ & 0.950 & 3.360 & 0.010 & Yes \\
\hline
\end{tabular}

SEM: standard error of the mean; Std Dev: standard deviation.

of $8.2 \%$ compressive strength at $1 \%$ fibre inclusion in mortar as compared to the control specimens. Pederneiras et al. [21] associated the reduced compressive strength to the large 
quantity of fibres in the mortar which produces voids and creates nonuniform distribution of fibres in the mortar. One-Way ANOVA test result shows a significant difference between the mix designs at $p<0.001$, as shown in Table 3 . Furthermore, the multiple comparison test results indicated that there is significant difference between the control and each of the fibre replacement content at $p \leq 0.001$. This means that the plantain pseudostem fibres (0.25 to $0.75 \%)$ and lime significantly and positively influenced the compressive strength of the cement mortar, while the plantain pseudostem fibres at $1 \%$ and lime significantly and negatively influenced the compressive strength of the cement mortar.

3.3. Compressive Strength and Strain Relationship. A parabolic curve of compressive stress and strain was obtained from the 28-day curing test of specimens, as shown in Figure 5. The highest stress was achieved from the $0.25 \%$ fibre specimens, followed by $0.5,0.75$, and $0 \%$ fibre specimens with the $1 \%$ fibre specimens recording the least stress. The result is in agreement with previous studies $[5,17,22,23]$ which obtained similar results. Inversely, the $1 \%$ plantain pseudostem fibre specimens obtained the highest strain, while the least was the control specimens. This implies that all the treatment group specimens performed better in strain than the control specimens. This is attributed to the inclusion of plantain pseudostem fibres and lime in the mortar which makes the specimens behave like an elastic material and improves the toughness of the specimens.

3.4. Tensile Strength. The tensile strength of the specimens recorded a continuous increase from curing days 7 to 28 , as shown in Figure 6. This is a normal trend of any cementbased material due to hydration. The highest tensile strength $(1.65 \mathrm{MPa})$ on the 28 -day of testing was achieved by the $1 \%$ plantain pseudostem fibre specimens, followed by the $0.5 \%$ $(1.6 \mathrm{MPa})$ and $0.25 \%(1.58 \mathrm{MPa})$, with the control specimens recording the least tensile strength $(1.45 \mathrm{MPa})$, as shown in Table 4 . There were $8.28,10.35,6.89$, and $13.80 \%$ increases in tensile strength, respectively, for $0.25,0.5,0.75$, and $1 \%$ plantain pseudostem fibre specimens over the control specimens. This result collaborates the findings in earlier studies [20,23]. To ascertain if the differences between the tensile strength of the specimens were significant or not, an ANOVA test performed obtained a $p$ value of 0.841 , suggesting that there is no statistically significant difference between the tensile strengths of the mix designs. It was further observed from the tensile strength test that the split fibre reinforced specimens were held together by the fibres after failure as compared to the control specimens which were completely separated apart. This implies that the addition of fibres in mortar has the ability to bridge cracks that are likely to develop in structures. Similar observations were made in earlier studies $[19,24]$. According to Danso et al. [24] the addition of fibres in matrix prevents cracks propagation as the fibres bridge across the cracks which also contributes to strength improvement. Conversely, the unreinforced specimens separated into two parts after the

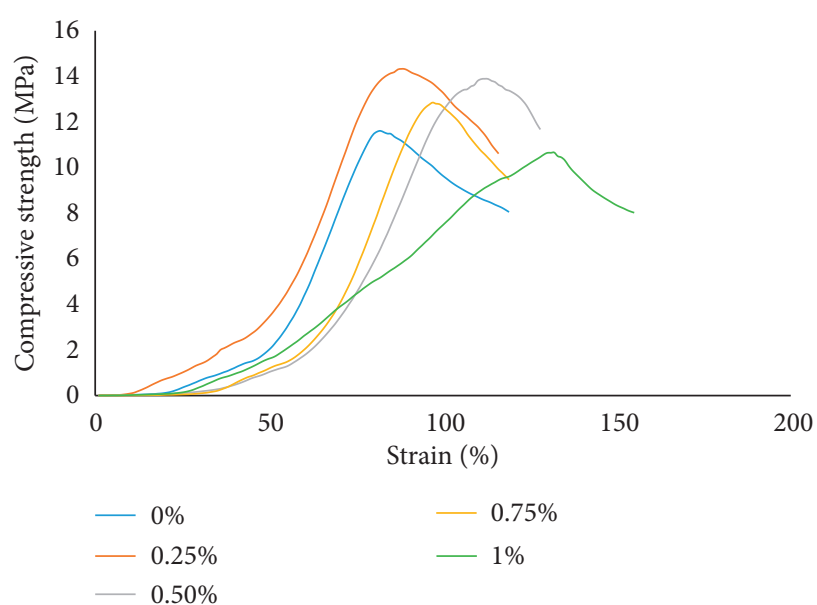

Figure 5: Compressive stress and strain relationship.

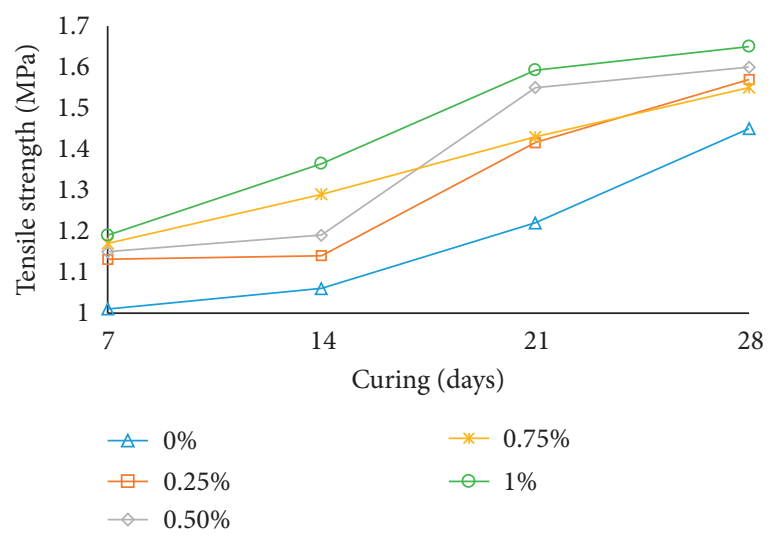

Figure 6: Tensile strength of specimens.

Table 4: Descriptive and One-Way RM ANOVA of tensile strength.

\begin{tabular}{lcccc}
\hline Specimen, mixture (\%) & $N$ & Mean & Std Dev & SEM \\
\hline 0 & 3 & 1.450 & 0.304 & 0.176 \\
0.25 & 3 & 1.579 & 0.154 & 0.088 \\
0.5 & 3 & 1.600 & 0.200 & 0.115 \\
0.75 & 3 & 1.550 & 0.180 & 0.104 \\
1 & 3 & 1.650 & 0.180 & 0.104 \\
\hline Source of variation & DF & SS & $F$ & $p$ \\
\hline B/t subjects & 2 & 0.0455 & & \\
B/t treatments & 4 & 0.0684 & 0.345 & 0.841 \\
Residual & 8 & 0.397 & & \\
Total & 14 & 0.511 & & \\
\hline
\end{tabular}

SEM: standard error of the mean; Std Dev: standard deviation.

tensile strength test. The unreinforced specimens were also found to have lower tensile strength as was also in the case of compressive strength as compared with the fibre reinforced specimens, which can be attributed to inadequate elastic behavior, low toughness, and lack of friction between the constituent materials of the unreinforced specimens. 


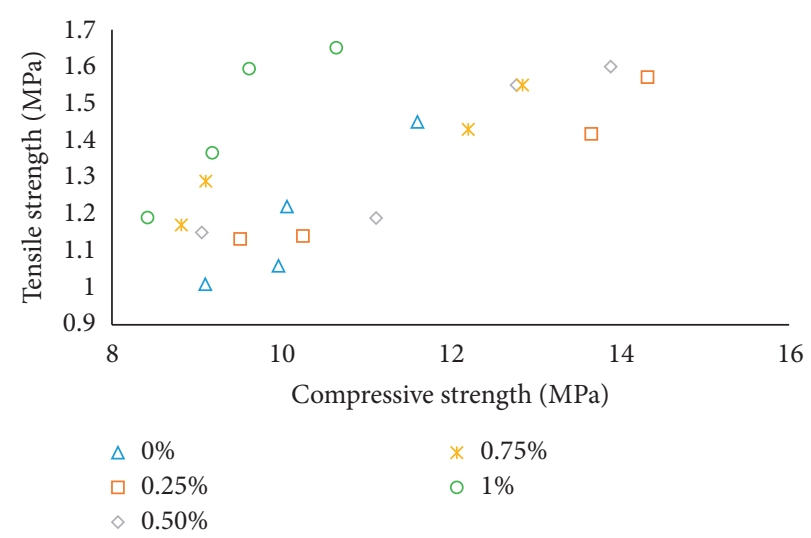

FIGURE 7: Relationship between compressive strength and tensile strength.

3.5. Relationship between Compressive Strength and Tensile Strength. A positive linear correlation was obtained between the compressive strength and tensile strength of cement mortar reinforced with plantain pseudostem fibres and lime, as shown in Figure 7 . The highest coefficient of determinant $\left(R^{2}\right)$ was 0.956 for $0.25 \%$ plantain pseudostem fibre specimens, implying a corresponding increase in both tensile and compressive strengths of the specimens. This was followed by $0.909,0.906,0.874$, and $0.869 R^{2}$ values, respectively, for $0.75,0,1$, and $0.5 \%$ plantain pseudostem fibre specimens. This result collaborates the findings of previous studies [17] on mortars reinforced with different natural fibres. This means the compressive strength is a good predictor of tensile strength of plantain pseudostem fibres and lime in cement mortar. The factors given by the compressive and tensile strengths of the specimens are 8.00, 9.07, 8.68, 8.29, and 6.46 for $0,0.25,0.5,0.75$, and $1 \%$, respectively, for plantain pseudostem fibre specimens. These factors are within the factors obtained by an earlier study [19] which recorded the factors between 6.6 and 14.9, while it was about double $(2.46$ to 3.58) of the factors obtained from another study [24] on soil-based matrix reinforced with natural fibres.

3.6. Microstructural and Oxide Composition Examination. Scanning electron microscope (SEM) analysis was conducted to examine the microstructural properties of the specimens. The images obtained are shown in Figure 8. The control (unreinforced mortar) specimen image (Figure 8(a)) shows the cement mortar with virtually no observed cracks. Conversely, the plantain pseudostem fibre reinforced lime mortar specimen (Figure 8(b)) shows some microcracks and voids. Development of voids in the cement matrix is not unusual as the material has the propensity of absorbing moisture. The microcracks usually occur due to manufacturing or handling deficiencies. The cracks are such that they cannot be seen by the naked eyes. The plantain pseudostem fibres are also clearly seen in the lime cement mortar, as shown in Figure 8(b). Studies have observed that the presence of random fibres in matrix generates bond, increases toughness, and reduces shrinkage in composite materials [25-27]. It is due to this that the incorporation of the plantain pseudostem fibre in the mortar resulted in the improved compressive and tensile strengths of the specimens. However, studies have also identified that increased quantity of fibres in the matrix causes the fibres to knock and overlap each other leading to lost cohesion with the matrix, and eventually weakening the composite material $[19,24]$. These factors contributed to the declined strength of the plantain pseudostem fibre specimens.

Energy dispersive spectrometer (EDS) analysis was also conducted to examine the oxides composition in the plantain pseudostem fibre-lime-cement mortar specimens, as shown in Figure 9. The EDS analysis was conducted on a spot where there was a mix of the lime cement mortar deposited on the plantain pseudostem fibre, as shown in Figure 9(a), and another spot on the lime cement mortar without the fibre, as illustrated in Figure 9(c). These spots were selected because they provided the opportunity to identify the chemical composition present in the combined fibre-lime-cement mortar (FLCM) and lime-cement mortar (LCM) for comparison. The elements shown in the result are oxygen (48.09\% FLCM and 52.39\% LCM), carbon $(22.03 \%$ FLCM and 21.92\% LCM), calcium (8.54\% FLCM and $9.84 \%$ LCM), silicon (8.40\% FLCM and 8.81\% LCM), aluminium (6.80\% FLCM and 6.68\% LCM), nitrogen (4.83\% FLCM and $0.00 \%$ LCM), potassium (0.88\% FLCM and $0.37 \%$ LCM), and sodium $(0.42 \%$ FLCM and $0.00 \%$ LCM) in weight concentration, as shown in Figures 9(b) and 9(d). It can be observed that the weight concentration of the elements such as oxygen, calcium, silicon, and aluminium were higher in the LCM than the FLCM. It can further be observed that the LCM specimens contain no amount of nitrogen and sodium.

The oxides identified in the FLCM and the LCM specimens are carbon $(\mathrm{C})$, calcium $(\mathrm{Ca})$, silicon $(\mathrm{Si})$, aluminium $(\mathrm{Al})$, nitrogen $(\mathrm{N})$, potassium $(\mathrm{K})$, and sodium $(\mathrm{Na})$, respectively, with their stoichiometric weight concentration of (42.44\% FLCM and $20.67 \%$ LCM), (16.45\% and $46.03 \%$ LCM), (16.19\% and $18.50 \%$ LCM), (13.10\% and $14.02 \%$ LCM), (9.31\% and $0.00 \%$ LCM), (1.70\% and $0.78 \%$ LCM), and $(0.82 \%$ and $0.00 \%$ LCM). It can again be observed that the LCM specimens contain no amount of nitrogen and sodium. The analysis indicates the presence of calcium silicate hydrate with a $\mathrm{Ca} / \mathrm{Si}$ ratio of 1.02 and 2.49 , respectively, for FLCM and LCM, which is within the maximum limit of 


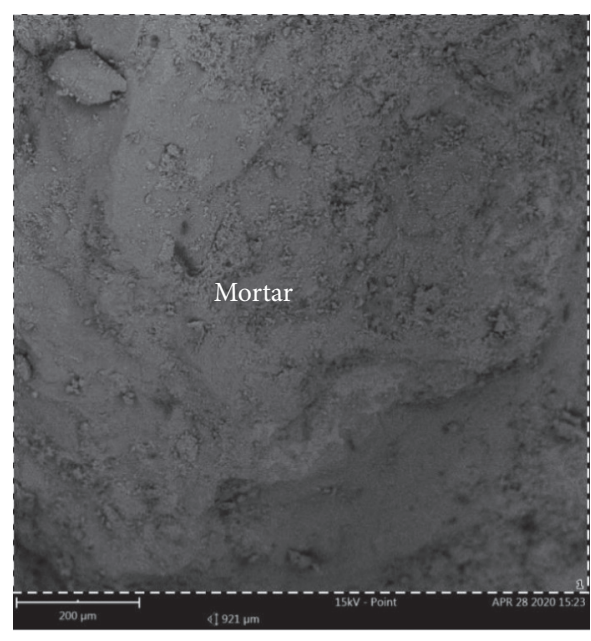

(a)

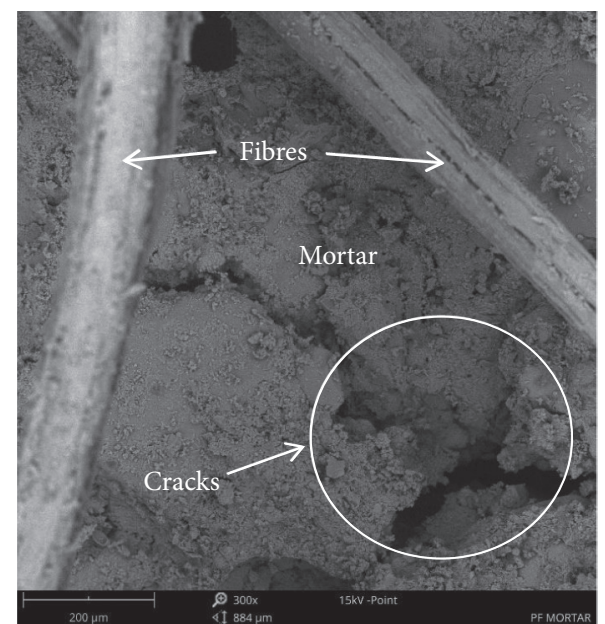

(b)

FIGURE 8: SEM images (300x) of unreinforced mortar and plantain pseudostem fibre reinforced mortar. (a) Image of unreinforced mortar. (b) Image of fibre reinforced mortar.

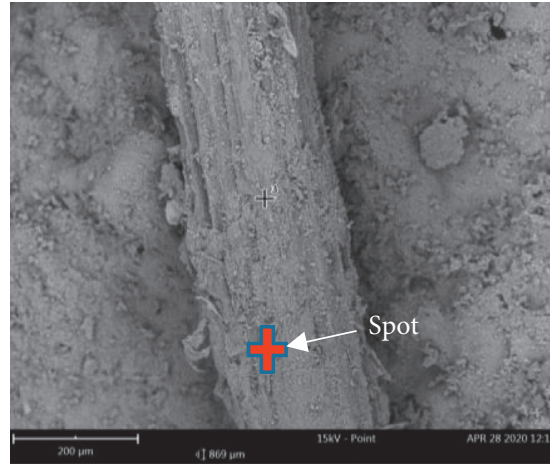

(a)

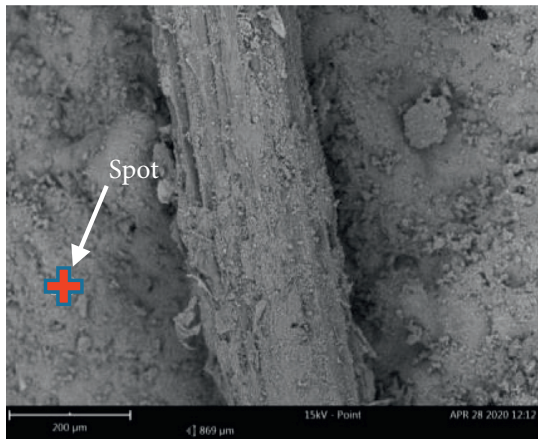

(c)

\begin{tabular}{|c|c|c|c|c|c|}
\hline & \multicolumn{3}{|c|}{ Element } & \multicolumn{2}{|r|}{ Oxide } \\
\hline & Symbol & $\begin{array}{l}\text { Atomic } \\
\text { conc. (\%) }\end{array}$ & $\begin{array}{l}\text { Wt. conc. } \\
(\%)\end{array}$ & Symbol & $\begin{array}{c}\text { Stoichiometric } \\
\text { wt. conc. (\%) }\end{array}$ \\
\hline \multirow{8}{*}{ (1) } & $\mathrm{O}$ & 50.17 & 48.09 & & \\
\hline & $\mathrm{C}$ & 30.62 & 22.03 & C & 42.44 \\
\hline & $\mathrm{Ca}$ & 3.56 & 8.54 & $\mathrm{Ca}$ & 16.45 \\
\hline & $\mathrm{Si}$ & 4.99 & 8.40 & $\mathrm{Si}$ & 16.19 \\
\hline & $\mathrm{Al}$ & 4.21 & 6.80 & $\mathrm{Al}$ & 13.10 \\
\hline & $\mathrm{N}$ & 5.76 & 4.83 & $\mathrm{~N}$ & 9.31 \\
\hline & K & 0.38 & 0.88 & $\mathrm{~K}$ & 1.70 \\
\hline & $\mathrm{Na}$ & 0.31 & 0.42 & $\mathrm{Na}$ & 0.82 \\
\hline
\end{tabular}

(b)

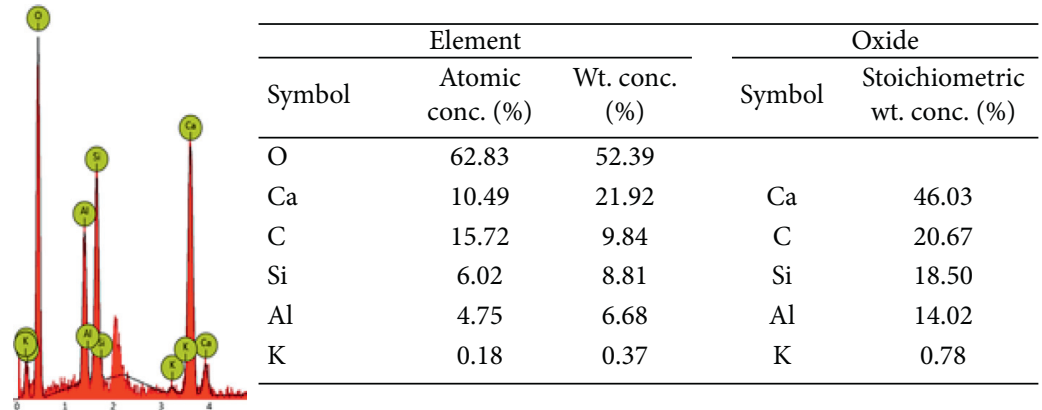

(d)

FIGURE 9: EDS analysis on specimen. (a) Selected spot image on fibre. (b) Chemical composition of matrix expressed as percentage of the elements and oxides for spot on fibre. (c) Selected spot image on mortar. (d) Chemical composition of matrix expressed as percentage of the elements and oxides for spot on mortar.

2.50 for mortar samples made with Portland cement as indicated by Kunther et al. [28]. The Al/Si ratio of 0.81 and 0.76 , respectively, for FCLM and CLM, and $\mathrm{Ca} / \mathrm{Si}$ ratio of 1.02 and 2.49, respectively, for FCLM and CLM as obtained in the specimen have impact on the mechanical properties of the material $[29,30]$. The high presence of elements such as $\mathrm{C}, \mathrm{Ca}, \mathrm{Si}$, and $\mathrm{Al}$ and their compositions helps in improving the bond characteristics of the mortar. 


\section{Summary and Conclusion}

The study investigated the properties of cement mortar reinforced with plantain pseudostem fibres and lime. It was revealed that

(1) Plantain pseudostem fibre-reinforced lime cement mortar obtained dry density values more than $2000 \mathrm{~kg} / \mathrm{m}^{3}$ which are acceptable for cement mortar for structural works

(2) $0.25 \%$ plantain pseudostem fibre-reinforced lime cement mortar recorded $23.4 \%$ compressive strength improvement over unreinforced mortar specimens with significant difference $(p<0.001)$

(3) There was between 6.89 and $13.80 \%$ increase in tensile strength of the plantain pseudostem fibrereinforced lime cement mortar over the unreinforced cement mortar specimens with no significant difference $(p=0.841)$

(4) There was a positive linear correlation between the compressive strength and tensile strength of cement mortar reinforced with plantain pseudostem fibres and lime with coefficient of determinant $\left(R^{2}\right)$ values between 0.909 and 0.869

(5) Plantain pseudostem fibre reinforced lime mortar specimen showed some microcracks and voids from the SEM analysis

(6) The EDS analysis showed the presence of calcium silicate hydrate with a $\mathrm{Ca} / \mathrm{Si}$ ratio of between 1.02 and 2.49 , and $\mathrm{Al} / \mathrm{Si}$ ratio of between 0.76 and 0.81 as the main oxide composition

The study, therefore, concludes that the incorporation of plantain pseudostem fibre and lime positively influenced the properties (such as compressive and tensile strengths) of the cement mortar with the $0.25 \%$ fibre content being recommended for construction application.

\section{Data Availability}

The data used to support the findings of this study are available from the corresponding author upon request.

\section{Conflicts of Interest}

The authors declare that they have no conflicts of interest.

\section{References}

[1] A. A. Umoh and S. P. A Nnana, "Study of Musa Paradisiaca pseudo-stem pith fluid as set-retarding admixture in cement paste and mortar," Emirates Journal for Engineering Research, vol. 19, no. 3, pp. 11-18, 2014.

[2] W. H. Zhu, B. C. Tobias, R. S. P. Coutts, and G. Langfors, "Aircured banana-fibre-reinforce cement composite," Cement \& Concrete Composite, vol. 16, pp. 1-6, 1994.

[3] E. J. Kumaat, M. R. I. A. J. Mondoringin, and H. Manalip, "Basic behaviour of natural banana stem fiber reinforced concrete under uniaxial and biaxial tensile stress,"
International Journal of GEOMATE, vol. 14, no. 44, pp. 166-175, 2018.

[4] F. Pacheco-Torgal and S. Jalali, "Cementitious building materials reinforced with vegetable fibres: a review," Construction and Building Materials, vol. 25, no. 2, pp. 575-581, 2010.

[5] M. Mostafa and N. Uddin, "Effect of banana fibers on the compressive and flexural strength of compressed earth blocks," Buildings, vol. 5, no. 1, pp. 282-296, 2015.

[6] H. Danso, "Identification of key indicators for sustainable construction materials," Advances in Materials Science and Engineering, vol. 2018, pp. 1-7, 2018.

[7] U. D. Akpabio, D. S. Udiong, and A. E. Akpakpan, "The physicochemical characteristics of plantain (Musa Paradisiaca) and banana (Musa Sapientum) pseudo-stem wastes," Advances in Natural and Applied Sciences, vol. 6, no. 2, pp. 167-172, 2012.

[8] V. Malarvizhi, V. Mahisha Vardhini, R. Aksayaa, S. Abinaya, and U. Arthi, "Experimental investigation of low cost slab using banana stem fibre," International Research Journal of Engineering and Technology, vol. 6, no. 3, pp. 286-289, 2019.

[9] N. Tirkey and G. B. Ramesh, "Experimental study on the banana fiber reinforced concrete," International Journal of Pure and Applied Mathematics, vol. 119, no. 18, pp. 20532056, 2018.

[10] S. Mukhopadhyay and B. Bhattacharjee, "Influence of fibre dispersion on compression strength of banana fibres reinforced concrete," Journal of Industrial Textiles, vol. 45, no. 5, pp. 957-964, 2016.

[11] BS EN 12620:2002+A1:2008, Aggregates for Concrete, British Standards Institution, London, UK, 2002.

[12] BS-12: 1996, Specification for Portland Cement, British Standards Institution, London, UK, 1996.

[13] BS EN 12390-2: 2009, Testing Hardened Concrete. Making and Curing Specimens for Strength Tests, British Standards Institution, London, UK, 2019.

[14] BS EN 12390-7:2009, Testing Hardened Concrete-Density of Hardened Concrete, British Standards Institution, London, UK, 2019.

[15] BS EN 12390-3:2009, Testing Hardened Concrete-Compressive Strength of Test Specimens, British Standards Institution, London, UK, 2019.

[16] BS EN 12390-6:2009, Testing Hardened Concrete-Tensile Splitting Strength of Test Specimens, British Standards Institution, London, UK, 2010.

[17] H. Danso and D. Manu, "Influence of coconut fibres and lime on the properties of soil-cement mortar," Case Studies in Construction Materials, vol. 12, pp. 1-12, 2020.

[18] B. Çomak, A. Bideci, and Ö. Salli Bideci, "Effects of hemp fibers on characteristics of cement based mortar," Construction and Building Materials, vol. 169, pp. 794-799, 2018.

[19] H. Danso, D. B. Martinson, M. Ali, and J. B. Williams, "Physical, mechanical and durability properties of soil building blocks reinforced with natural fibres," Construction and Building Materials, vol. 101, pp. 797-809, 2015.

[20] N. G. Ozerkan, B. Ahsan, S. Mansour, and S. R. Iyengar, "Mechanical performance and durability of treated palm fiber reinforced mortars," International Journal of Sustainable Built Environment, vol. 2, no. 2, pp. 131-142, 2013.

[21] C. M. Pederneiras, M. do Rosário Veiga, and J. de Brito, "Effects of the incorporation of waste fibres on the cracking resistance of mortars: a review," International Journal of Green Technology, vol. 4, pp. 38-46, 2018.

[22] M. O. Bouffoue, C. H. Kouakou, K. C. Kouadio, A. A. Assande, S. Ouattara, and E. Emeruwa, "Experimental 
method to measure the mechanic behavior of compressed earth blocks in continuous compression," Journal of Asian Scientific Research, vol. 5, no. 1, pp. 31-37, 2015.

[23] K. N. Indira, J. Parameswaranpillai, and S. Thomas, "Mechanical properties and failure topography of banana fiber PF macrocomposites fabricated by RTM and CM techniques," ISRN Polymer Science, vol. 2013, Article ID 936048, 8 pages, 2013.

[24] H. Danso, D. B. Martinson, M. Ali, and J. Williams, "Effect of fibre aspect ratio on mechanical properties of soil building blocks," Construction and Building Materials, vol. 83, pp. 314-319, 2015.

[25] M. Maalej, V. C. Li, and T. Hashida, "Effect of fiber rupture on tensile properties of short fiber composites," Journal of Engineering Mechanics, vol. 121, no. 8, pp. 903-913, 1995.

[26] A. Slosarczyk, "The influence of nonetallic and metallicfibres on the mechanical properties of cement mortars," in International Symposium on Brittle Matrix Composite 10, J. Olek, A. M. Brandt, M. A. Glinicki et al., Eds., Woodhead Publishing, Warsaw, Poland, 2012.

[27] H. Danso, D. B. Martinson, M. Ali, and J. B. Williams, "Mechanisms by which the inclusion of natural fibres enhance the properties of soil blocks for construction," Journal of Composite Materials, vol. 51, no. 27, pp. 3835-3845, 2017.

[28] W. Kunther, B. Lothenbach, and J. Skibsted, "Influence of the $\mathrm{Ca} / \mathrm{Si}$ ratio of the $\mathrm{C}-\mathrm{S}-\mathrm{H}$ phase on the interaction with sulfate ions and its impact on the ettringite crystallization pressure," Cement and Concrete Research, vol. 69, pp. 37-49, 2015.

[29] C. A. Botero, E. Jimenez-Piqué, R. Martín, T. Kulkarni, V. K. Sarin, and L. Llanes, "Nanoindentation and nanoscratch properties of mullite-based environmental barrier coatings: influence of chemical composition - Al/Si ratio," Surface and Coatings Technology, vol. 239, pp. 49-57, 2014.

[30] H. Danso, "Effect of rice husk on the mechanical properties of cement-based mortar," Journal of The Institution of Engineers (India): Series D, 2020. 